\title{
Colocalization with MMP-7 in the Distal Colon is Crucial for Syndecan-2 Shedding in Dextran Sulfate Sodium-Induced Colitis Mice
}

\author{
Heejeong Hong' \\ Hyun-Kuk Song ' \\ Bohee Jang' \\ Eunhye Park' \\ Dong Soo $\mathrm{Han}^{2}$ \\ Seong-Eun $\mathrm{Kim}^{3}$ \\ Eok-Soo Oh'
}

'Department of Life Sciences, Ewha Womans University, Seoul, South Korea; ${ }^{2}$ Department of Internal Medicine, Hanyang University College of Medicine, Guri, South Korea; ${ }^{3}$ Department of Internal Medicine, Ewha Womans University School of Medicine, Ewha Medical Research Institute, Seoul, South Korea
Correspondence: Eok-Soo Oh

Department of Life Sciences, Ewha Womans University, 52, Ewhayeodae-gil,

Seodaemoon-Gu, Seoul, 03760, South Korea

Tel +82-2-3277-3761

$\mathrm{Fax}+82-2-3277-3760$

Email OhES@ewha.ac.kr
Introduction: Syndecan-2 expression is elevated during chronic inflammation and cancer development, and its shedding is observed in cancer patients. However, it remained unknown whether inflammation triggers syndecan-2 shedding.

Methods: The colitis model was produced in C57BL/6 mice by oral administration of 2-3\% dextran sulfate sodium (DSS) in the drinking water. Syndecan-2 and MMP-7 expression levels in tissues and cells were detected by real-time PCR, Western blotting, and immunohistochemistry. Shed syndecan-2 levels were detected by slot blotting. For tissue culture, colon tissues were divided into proximal, transverse, and distal parts, and incubated in culture media.

Results: In C57BL/6 mice with DSS-induced colitis, syndecan-2 shedding began to increase after week 12 of chronic inflammation and continued to increase at week 15 . The level of shed syndecan- 2 correlated with the colocalization of syndecan-2 and MMP-7 in distal colon tissues. The mRNA expression of IL-6 was increased specifically in trans-distal colon tissues from weeks 9 to 15 . IL-6 induced syndecan- 2 expression and shedding and MMP-7 expression in ex vivo-cultured distal colon tissues and adenoma cell lines derived from the distal colon. IL-6 treatment induced STAT3 phosphorylation and MMP-7 expression in DLD-1 cells. The application of MMP-7 to ex vivo-cultured colon tissues increased the shedding of syndecan-2 to the culture medium.

Conclusion: Our findings suggest that chronic inflammation induces syndecan-2 shedding via the site-specific colocalization of syndecan-2 with MMP-7 in the distal colon.

Keywords: chronic inflammation, syndecan-2, MMP-7, shedding

\section{Plain Language Summary}

Chronic inflammation is linked to a wide variety of diseases, including inflammatory bowel disease (IBD) such as Crohn's disease and ulcerative colitis. Since IBD is a leading cause of colon cancer, with patients increasing over the years, it is important to develop biomarkers to properly manage the chronic inflammation. One of the interesting features of colon cancer is the shedding of the cell surface of proteoglycan syndecan-2, which is known to be upregulated during the development of colon cancer. Here, we show for the first time that chronic inflammation also causes syndecan-2 shedding. In particular, syndecan- 2 shedding is site-specifically correlated with colocalization of syndecan-2 and MMP-7 in trans-distal colon tissues, and IL-6, increased during chronic inflammation, directly regulates MMP-7 expression and syndecan-2 shedding. Because shed syndecan-2 levels reflect site-specific changes during chronic inflammation, syndecan-2 shedding may be important as a biomarker of chronic inflammation. Therefore, this study could facilitate future development for the diagnosis and treatment of diseases associated with the inflammatory response as a biomarker of chronic inflammation. 


\section{Introduction}

The inflammatory response is a defense mechanism that evolved to protect higher organisms from infection and injury. ${ }^{1,2}$ Acute inflammation is a short-term process that occurs in response to tissue injury, usually appearing within minutes to hours, whereas chronic inflammation continues for prolonged periods of several months to years, and is linked to certain diseases (eg, heart disease and stroke) and autoimmune disorders (eg, rheumatoid arthritis and lupus). Notably, chronic inflammation has long been linked to cancer: If inflammation is chronically unregulated, there is a high possibility of tumorigenesis and/or tumor progression. About $20 \%$ of cancers begin with chronic inflammation, which also promotes tumorigenesis by producing numerous cytokines and chemokines. Moreover, since cancers induced by chronic inflammation are usually genetically stable, they typically exhibit a high level of cancer drug resistance. ${ }^{3}$ One mechanism used by the immune system to regulate inflammation is the shedding (via cleavage of the extracellular domain) of a modulating protein. Since leukocyte recruitment is a key step in basic inflammatory responses, it is critically important to precisely regulate the shedding of adhesion molecules, such as L-selectin, ICAM-1 and VCAM-1, which contribute to leukocyte recruitment. The extracellular domain of desmoglein-2 is cleaved by the proinflammatory cytokines, IL- $1 \beta$ and TNF- $\alpha$, in the mucosal barrier, and this shedding may help rebuild the colonic structure after inflammation. ${ }^{4}$ TNF- $\alpha$ is a well-known proinflammatory cytokine that is initially produced as a type II transmembrane protein; when an inflammatory response is triggered, its ectodomain is cleaved to activate the cytokine. Activated TNF- $\alpha$ has been shown to initiate the TNF- $\alpha$ dependent cytokine cascade to induce severe skin inflammation. ${ }^{5}$ Moreover, the shedding of IL-6 receptor a and HB-EGF was found to occur during lung infection; this boosts the inflammatory response and the ectodomain cleavage of CD44, leading to the recruitment of leukocytes during eosinophilic pneumonia. ${ }^{6,7}$ Therefore, the existing evidence indicates that shedding is a general biological mechanism for the regulation of various inflammationassociated diseases, including cancer.

During cancer progression, the shedding of cadherins is a very common event. The cleavage of $\mathrm{P}$-cadherin is related to breast cancer: ${ }^{8,9}$ Soluble P-cadherin (sP-cadherin) was highly detected in nipple aspirate fluids at a level that depended on the cancerous stage, ${ }^{9}$ and elevation of sP-cadherin was described as enhancing the migration and invasion of breast cancer. ${ }^{8,9}$ Meanwhile, the type III TGF- $\beta$ receptor (T $\beta$ RIII) was found to exert different functions before and after its shedding: T $\beta R I I I$ itself affects cancer cells in a cancer typespecific manner, whereas soluble T $\beta$ RIII (sTRRIII) inhibits cellular invasiveness in various types of cancer, such as pancreatic, non-small cell lung and breast cancer. ${ }^{10-12}$

Syndecan is a transmembrane-bounded heparan sulfate proteoglycan that functions as a cell surface receptor to mediate and regulate both inflammation and cancer. Since heparan sulfate binds to various cell surface and matrix molecules, including cytokines and chemokines, syndecan is able to modulate inflammatory cell maturation, activation and other related functions. ${ }^{13}$ Interestingly, the extracellular domain shedding of syndecans is also common during inflammation and cancer. For instance, syndecan-1, which is predominantly expressed in the epithelium, is cleaved by matrix metalloproteinases (MMPs), and acts to attenuate neutrophilic inflammation by removing chemokines. ${ }^{14}$ In lung inflammation, MMP-7 triggers shedding of the syndecan- 1 extracellular domain, which inhibits the recruitment of Th2 cells to the inflamed area and thereby relieves inflammation. ${ }^{15}$ On the other hand, elevation of the serum level of shed syndecan-1 in colitisinduced mice accelerates colonic inflammation, and mutation of the cleaved domain attenuates this inflammatory response. ${ }^{16,17}$ Moreover, shed syndecan-4 cleaved by MMP-2 accelerates inflammation by triggering chemokine accumulation in airway smooth muscle cells, and oxidative stress induces syndecan-4 shedding in atrial tissues. ${ }^{18,19}$

Syndecan-2 is not expressed in the normal epithelium, but rather exhibits upregulation during chronic inflammation and cancer progression. ${ }^{20,21}$ Studies have shown that: chronic inflammation can induce the expression of colonic syndecan- $2 ;^{20}$ induced syndecan-2 expression in inflammatory macrophages can regulate fibroblast growth factor activity; ${ }^{22}$ and syndecan-2 expressed on activated primary human CD4+ lymphocytes can regulate $\mathrm{T}$ cell activation. ${ }^{23}$ These findings suggest that syndecan-2 may also regulate inflammatory responses. Interestingly, during acute inflammation, syndecan-2 expression was up-regulated predominantly in the proximal colon of colitis-induced mice, ${ }^{24}$ suggesting that syndecan-2 plays site-specific functional roles in the colonic epithelium. Our group further showed that IL-1 $\alpha$ induces syndecan-2 shedding in colorectal cancer cell lines, ${ }^{25}$ and that shed syndecan-2 stimulates colorectal cancer activities. ${ }^{21}$ However, while the level of shed syndecan-2 is known to be elevated in colorectal cancer, no previous study has examined shed syndecan-2 in the 
context of the inflammatory response. Here, we used mouse models of chronic colitis to examine the mechanism responsible for syndecan-2 shedding during inflammation.

\section{Materials and Methods Materials}

Monoclonal and polyclonal anti-syndecan-2 were produced by AdipoGen Inc. (Incheon, South Korea). The antibody against MMP-7 was purchased from Cell Signaling Technology (Danvers, MA, USA), and syndecan-1 from Sino Biological Inc. (Beijing, China). IL-1 $\alpha$, IL-1 $\beta$, IL-6, and IL-17A were purchased from R\&D Systems (Minneapolis, MN, USA). The antibody against MMP-7 polyclonal and MMP-14 were purchased from Abcam (Cambridge, England). Human recombinant MMP-7 enzyme and JSI-124 were purchased from SigmaAldrich (St. Louis, MO, USA) and GM6001 was purchased from Millipore (Billerica, MA, USA).

\section{Cell Culture}

The human colon cancer cell lines (HCT116, SNU-1235, DLD-1 and SW480) were purchased from Korean cell line bank (Seoul, South Korea). HCT116 cells were maintained in McCoy's 5A medium (Hyclone, Logan, UT, USA), SNU-1235 cells in RPMI1640 medium (Hyclone, Logan, UT, USA), DLD-1 cells in DMEM medium (Hyclone, Logan, UT, USA) and SW480 cells in DMEM/F12 medium (Welgene, Daegu, South Korea) supplemented with $10 \%(\mathrm{v} / \mathrm{v})$ fetal bovine serum and gentamicin $(50 \mathrm{mg} / \mathrm{mL})$ (Sigma-Aldrich, St. Louis, MO, USA). The cells were cultured at $37^{\circ} \mathrm{C}$ in a humidified $5 \% \mathrm{CO} 2$ atmosphere.

\section{Mice}

The seven-week-old male C57BL/6 mice were purchased from Central Lab Animal, Inc. (Seoul, South Korea). All procedures in the animal studies were performed in accordance with the guidelines of and under approval by the Institutional Animal Care and Use Committees (IACUCs) of Ewha Womans University (No. 15-044 and 16-069) and Hanyang University (No. HY-16-0066 and HY-17-0007).

\section{Animal Models}

Acute colitis model was produced in mice by oral administration of $3 \% \mathrm{DSS}[35-50 \mathrm{kDa}]$ in the drinking water for 4 days followed by 6 days on tap water (each group $n=10$ ). Mid-term colitis model was administered with $2 \%$ DSS in drinking water for 5 days and followed by 5 days of tap water (each group $\mathrm{n}=10$ ) and repeated the cycle 3 times. $2 \%$ DSS was orally delivered to chronic colitis model for a week and followed by two weeks of tap water (each group $n=7$ ) and repeated the cycle 5 times.

\section{Slot Blotting}

Conditioned media were slot-blotted onto a $0.45-\mu \mathrm{m}$ nitrocellulose membrane (GE Healthcare, Chicago, IL, USA) in a Bio-Rad apparatus (Bio-Rad, Hercules, CA, USA). After blotting, the membrane was stained with Ponceau $\mathrm{S}$. The membrane was then washed in $0.05 \%$ Tween- 20 in Trisbuffered saline (TBS: $50 \mathrm{mM}$ Tris- $\mathrm{HCl}, \mathrm{pH} 7.4,150 \mathrm{mM}$ $\mathrm{NaCl}$ ), blocked in TBS-T with 5\% skim milk, washed, and probed with anti-syndecan-2 or -1 (1:1000) for overnight at $4^{\circ} \mathrm{C}$. Signals were detected using an Odyssey CLx imager (LICOR Biosciences, Lincoln, NE, USA), and the data were analyzed with the Image Studio Lite software (LI-COR Biosciences).

\section{Immunohistochemical Staining of Tissue Samples}

After mice were sacrificed, their colons were Swiss-rolled, fixed in $4 \%$ formalin, and embedded in paraffin. Each paraffin block was sequentially sectioned at $4 \mu \mathrm{m}$, and the sections were mounted on slides. Immunohistochemical staining was performed using previously described method. ${ }^{20}$ Briefly, the sections were rinsed and endogenous peroxidase activity was blocked with $3 \%$ hydrogen peroxide. The sections were then washed with PBS, blocked with M.O.M ${ }^{\mathrm{TM}}$ Mouse IgG blocking reagent (Vector Laboratories, Inc., Burlingame, CA, USA), and incubated overnight with diluted primary antibodies. The sections were washed with PBS and incubated with biotinylated secondary antibodies for $1 \mathrm{hr}$ and immunostaining was visualized with a Vectastain ABC kit, using DAB as a substrate (Vector Laboratories, Inc.). The sections were rinsed, dehydrated, mounted, and covered with coverslips. The tissue slides were observed under a light microscope (Leica DM1000 LED; Leica Microsystems, Wetzlar, Germany) and images were captured using an LAS Image Analyzer (LAS ver 4.0; Leica Microsystems).

\section{Double-Immunofluorescence Staining}

For double labeling with syndecan-2, MMP-7, and IL-6, $4 \mu \mathrm{m}$ paraffin sections were used. The tissue sections were prepared as described above. In brief, the section was washed with PBS and then blocked with M.O.M Mouse 
IgG blocking reagent (Vector laboratories, Burlingame, CA, USA) at $4^{\circ} \mathrm{C}$ overnight. On the next day, the tissue slides were incubated with diluted primary antibody mixtures antisyndecan-2 (1:300) and MMP-7 (1:100) in antibody diluent (Dako, Santa Clara, CA, USA) at $4^{\circ} \mathrm{C}$ overnight and were rinsed with PBS the next day. Then, the slides were incubated with secondary antibody mixture Texas Redconjugated donkey anti-rabbit (Elisa technologies, Gainesville, FL, USA) and FITC-conjugated donkey antimouse (Elisa technologies) for $2 \mathrm{hr}$ at room temperature. The tissue slides were observed under Eclipse Ts2R-FL fluoresce microscope (Nikon Corporation, Minato-ku, Tokyo, Japan) after the sections were mounted in fluorescence mounting solution with DAPI (Vector Laboratories, Burlingame, CA, USA) and images were captured using an imaging software (Nis-Element BR ver 5.01; Nikon imaging software).

\section{Real-Time PCR (qPCR) and RT-PCR}

Expression levels of target genes were measured by qPCR for colon tissues and by RT-PCR for cell lines. Total RNA was extracted using the easy-BLUE reagent (iNtRON Biotech.) as suggested by the manufacturer. Lithium chloride purification was performed to remove any contaminating DSS, which can inhibit reverse transcriptases and polymerases. Approximately $3 \mu \mathrm{g}$ of RNA was used to generate cDNA with AMV reverse transcriptase and random primers (Promega US, Madison, WI, USA). Aliquots of the resulting cDNA were amplified using the specific primers listed in Table 1. Real-time PCR was performed by the CFX96 ${ }^{\mathrm{TM}}$ Real-Time PCR Detection System (Bio-Rad) in a two-step procedure using SensiFASTTM SYBR $^{\circledR}$ Hi-ROX Kit
(BioLine, London, UK) using the specific primers (Table 1). All reactions were performed in a 96 well plate using the following cycling conditions: 40 cycles of $95^{\circ} \mathrm{C}$ for $15 \mathrm{~s}$, and $60^{\circ} \mathrm{C}$ for $30 \mathrm{~s}, 72^{\circ} \mathrm{C} 1 \mathrm{~min}$. Using the $\mathrm{CT}$ (deltadelta $\mathrm{CT}$ ) method, the value of each control sample was set at 1 and used to calculate the fold-change of target genes. For the RT-PCR, aliquots of the resulting cDNA were amplified using the specific primers (Table 1). After an initial denaturation at $94^{\circ} \mathrm{C}$ for $5 \mathrm{~min}$, samples were subjected to 30 cycles of denaturation at $94^{\circ} \mathrm{C}$ for $30 \mathrm{~s}$, annealing at $55^{\circ} \mathrm{C}$ for $60 \mathrm{~s}$, and extension at $72^{\circ} \mathrm{C}$ for $60 \mathrm{~s}$.

\section{Tissue Culture}

Normal or colitis induced (3\% DSS, 4 days) mouse colon tissues were collected, washed several times with PBS $(\mathrm{n}=10$ each), dissected longitudinally, and then divided into proximal, transverse, and distal parts. Each part was incubated in medium supplemented with or without mouse IL-1 $\beta$ $(10 \mathrm{ng} / \mathrm{mL})$ or IL-6 (40 ng/mL) for $24 \mathrm{hr}$. Media were collected, centrifugated and supernatants were used for slot blotting. Colonic tissues were collected for qRT-PCR.

\section{Multiplex Cytokine Analysis}

The selected cytokines were determined by Koma Biotech (Seoul, South Korea) using a Multiplex Map Mouse Magnetic Bead Panel (Millipore, Billerica, MA, USA) as previously described methods. ${ }^{20}$

\section{Reporter Assay}

DLD-1 cells plated to 12-well plates were co-transfected with $0.8 \mu \mathrm{g}$ of pGL3-basic vector or MMP-7(-2344) reporter

Table I List of Primers

\begin{tabular}{|c|c|c|c|}
\hline Gene & & Forward Primer & Reverse Primer \\
\hline qPCR & $\begin{array}{l}\text { mSDC2 } \\
\text { hSDC2 } \\
\text { mMMP-7 } \\
\text { hMMP-7 } \\
\mathrm{mIL-I} \alpha \\
\mathrm{mIL}-1 \beta \\
\mathrm{mIL}-6 \\
\mathrm{mIL}-17 \mathrm{~A} \\
\mathrm{mGAPDH} \\
\text { hGAPDH }\end{array}$ & $\begin{array}{l}\text { TTCAGGAGTATATCCTATTGATGATGA } \\
\text { CTGCCCCTAAACTTCTGCCGT } \\
\text { CCCGGTACTGTGATGTACCC } \\
\text { GGCTTTAACATGTGGGGCA } \\
\text { GCCTTATTTCGGGAGTCTAT } \\
\text { CCTTCCAGGATGAGGACATGA } \\
\text { TAGTCCTTCCTACCCCAATTTCC } \\
\text { TCCAGAAGGCCCTCAGACTA } \\
\text { GGAAGGGCTCATGACCACA } \\
\text { CCTCAAGATCATCAGCAAT }\end{array}$ & $\begin{array}{l}\text { ACTCTCTATGTCTTCATCAGCTCCT } \\
\text { CTTGTTGGTTTCTGCACTCCC } \\
\text { AATGGAGGACCCAGTGAGTG } \\
\text { GGCCCATCAAATGGGTGAGA } \\
\text { TAGGGTTTGCTCTTCTCTTACA } \\
\text { TGAGTCACAGAGGATGGGCTC } \\
\text { TTGGTCCTTAGCCACTCCTTC } \\
\text { ACACCCACCAGCATCTTCTC } \\
\text { CAGTGAGCTTCCCGTTCAG } \\
\text { CCATCCACAGTCTTCTGGGT }\end{array}$ \\
\hline RT-PCR & $\begin{array}{l}\text { hSDC2 } \\
\text { hMMP-7 } \\
\text { hGAPDH }\end{array}$ & $\begin{array}{l}\text { CATCTCCCCTTTGCTAACGGC } \\
\text { GGTCACCTACAGGATCGTATCATAT } \\
\text { CCACCCATGGCAAATTCCATGGCA }\end{array}$ & $\begin{array}{l}\text { TAACTCCATCTCCTTCCCCAGG } \\
\text { CATCACTGCATTAGGATCAGAGGAA } \\
\text { TCTAGACGGCAGGTCAGGTCCACC }\end{array}$ \\
\hline
\end{tabular}


constructs together with $0.8 \mu \mathrm{g}$ of $\mathrm{pCMV} / \beta$-galactosidase (Clontech, Palo Alto, CA) (normalizing control), using the Lipofectamine reagent (Invitrogen). Four hours posttransfection, the cultured media were replaced with fresh media and the cells were serum starved with $1 \%$ FBS for 16 $\mathrm{hr}$. The cells were then treated with IL-6 $(40 \mathrm{ng} / \mathrm{mL})$ in the absence or presence of $0.5 \mu \mathrm{M}$ JSI-124 (a selective inhibitor of the JAK/STAT3 signaling pathway) for $24 \mathrm{hr}$, washed with PBS and lysed with the buffer provided in the luciferase assay kit (Promega, Madison, WI). Soluble extracts were harvested and assayed for luciferase and $\beta$-galactosidase activities, according to the manufacturer's instructions. To normalize the luciferase values for transfection efficiency, the results are presented as relative luciferase activities (luciferase activity/ $\beta$-galactosidase activity).

\section{Statistical Analysis}

Data are presented as the mean \pm standard error of the mean (SEM) from each independent experiment. Statistical analysis was performed using the one-way ANOVA followed by Bonferroni post hoc test or Student's $t$ test. A value of $\mathrm{p}<$ 0.05 was considered to indicate a statistically significant difference. The Pearson single-correlation coefficient was used to compare the syndecan-2 positive area and inflammatory area or serum shed syndecan-2 level. Statistical significance was accepted when $\mathrm{p}<0.05$. All data were analyzed SPSS version 20.0 (SPSS, Chicago, IL).

\section{Results}

\section{The Extracellular Shedding of Syndecan-2 Occurs During Chronic Inflammation}

We previously reported that syndecan-2 expression is increased during colon cancer formation ${ }^{20}$ and the extracellular shedding of syndecan-2 increases during the process of carcinogenesis. ${ }^{21}$ We also recently reported evidence suggesting that syndecan-2 expression might be increased during the inflammatory response. ${ }^{20,24}$ Here, we further investigated whether syndecan-2 shedding occurs during inflammation. First, acute inflammation on syndecan-2 shedding was assessed. C57BL/6 mice were exposed to $3 \%$ DSS in their drinking water for 4 days (acute phase) followed by fresh drinking water (from the tap) for 6 days (recovery phase). In our slot blotting analysis, we failed to detect syndecan-2 throughout the experiment, indicating that shed syndecan-2 was not induced or altered under acute DSS-induced colitis (Figure 1A). When medium-term inflammatory colitis was induced by three cycles of a 5 -day exposure to $2 \%$ DSS followed by 5 days of recovery, detectable level of secreted syndecan-2 in serum was observed, but the quantified level was not significantly different from that of the vehicle control (Figure 1B). This suggested that syndecan-2 shedding requires a long-term inflammatory reaction. To confirm this, we induced chronic colitis by applying five cycles of a 7-day exposure to $2 \%$ DSS followed by 14 days of recovery according to the protocol previously used. ${ }^{26,27}$ The serum from week 13 (just after the DSS administration ended), 14 (after 1 week of recovery) and 15 (after 2 weeks of recovery) was collected. Compared to vehicle control mice, those subjected to the chronic colitis-inducing protocol exhibited elevated serum levels of shed syndecan-2 at the three tested time points, yet only week 15 showed significant elevated shed syndecan-2 (Figure 1C). We further collected serum at the end of each cycle and performed slot blotting. As shown in Figure 1D, the shed syndecan-2 levels were begun to elevate at week 9 with the significantly highest level seen at week 15 . Since the shedding of syndecan-1 is known to increase during the inflammatory response, ${ }^{16,17}$ we detected the amount of shed syndecan-1 in the same sera. However, the serum level of shed syndecan-1 was not elevated at weeks 9 to 15 in our model (Figure 1E). These data suggest that the extracellular shedding of syndecan-2, but not syndecan-1, occurs during chronic inflammation.

\section{Serum Levels of Shed Syndecan-2 Correlate with Its Expression Levels at Trans-Distal Colon}

Although we previously reported that syndecan-2 expression was predominantly elevated at the proximal colon during acute inflammation, our above data showed that acute inflammation failed to induce syndecan-2 shedding (Figure 1A). In an effort to understand this discrepancy, we examined the expression pattern of syndecan-2 at weeks 9 to 15 of chronic inflammation, when the elevated serum levels of shed syndecan-2 were detected (Figure 2). At week 9, syndecan-2 expression was increased throughout the colon, most prominently in the proximal colon. Thereafter, from weeks 12 to 15 , the expression of syndecan-2 gradually increased in the transdistal colon (Figure 2A). Similarly, the mRNA expression of syndecan-2 was most clearly elevated in the proximal colon at week 9, but it was elevated throughout the colon at weeks 12 and 15 (Figure 2B). On the other hand, the mRNA expression levels of syndecan-1 were progressively reduced under chronic inflammation (weeks 9-15), compared to that seen in vehicle control mice (Figure 2B). For further analysis, we 
A

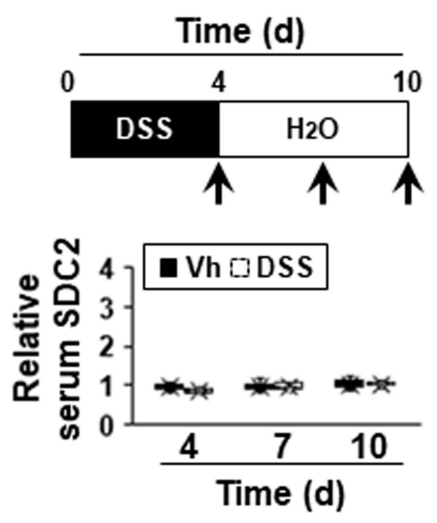

B

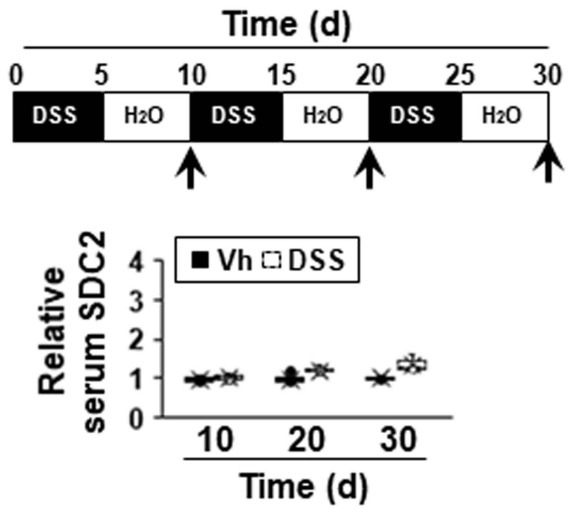

D

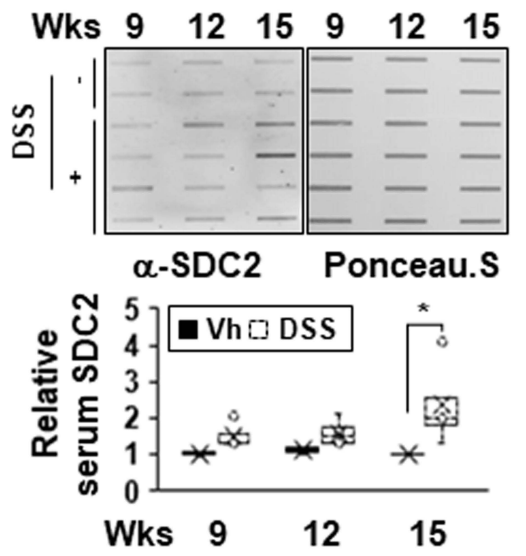

E

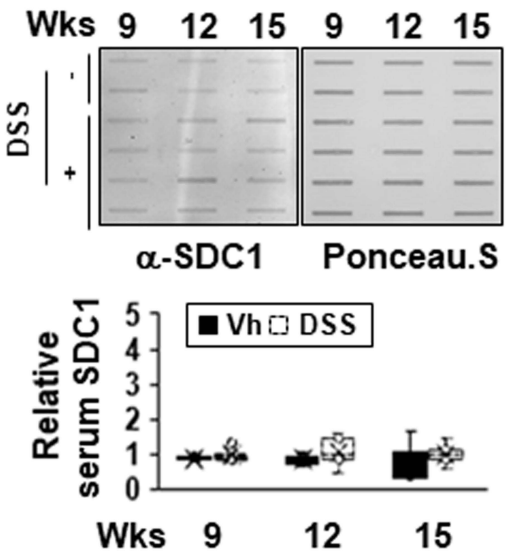

Figure I The extracellular shedding of syndecan-2 occurs during chronic inflammation. (A and B) Seven-week-old C57BL/6 mice were administrated with $3 \%$ (A) or $2 \%$ (B) DSS ( $n=6$ mice per group) and sacrificed for the indicated periods of time. Mice serum were collected and analyzed by slot blotting with anti-syndecan-2 polyclonal antibody. Quantitative analysis of shed syndecan-2 levels in mice serum were performed using box-whisker plot. The shed syndecan-2 level in vehicle mice was used as a control. (C) Administration of $2 \%$ DSS for a week and two weeks of recovery phase was I cycle and repeated this cycle for 5 times. Mice serum from indicated time points were collected and analyzed by slot blotting with anti-syndecan-2. Protein loading in blots were determined by Ponceau S staining. Box-whisker plot represented the level of shed syndecan-2 (SDC2) using shed syndecan-2 level of vehicle as a control. (D and E) Administration of $2 \%$ DSS was performed as described in (C). Mice serum from indicated time points were collected and analyzed by slot blotting with anti-syndecan-2 (D) and anti-syndecan-I antibody (E). Box-whisker plot represented the level of shed syndecan-2 (SDC2, (D) and -I (SDCI, (E) using shed syndecan-2 and -I level of vehicle as a control. *p $<0.05$.

digitally colored the regions that stained positive for syndecan2 in the proximal or trans-distal colon and calculated the expression area at each time point for each site (Figure 2C). The proximal colons of inflamed mice showed significantly up-regulated syndecan-2 expression (42\%) at week 9 and maintained this elevated expression at week 15 (58\%). However, the expression of syndecan-2 increased more slowly and to a lower level in the trans-distal colon compared to the proximal colon. At 9 and 12 weeks, 18\% and 37\%, respectively, of the trans-distal colon expressed syndecan-2, suggesting that the elevation of shed syndecan- 2 was associated with the increased expression of syndecan- 2 in the trans-distal colon. Indeed, the area of syndecan- 2 expression was well correlated with the inflammatory area $(\mathrm{r}=0.710, \mathrm{P}=0.010$, Figure 2D) and serum shed syndecan-2 level $(r=0.717$, $p=0.002$, Figure $2 E$ ) in the trans-distal colon. Since the elevation of shed syndecan- 2 during chronic inflammation appears to be associated with the upregulation of syndecan-2 expression in the trans-distal colon, we propose that syndecan-2 expressed in the trans-distal region is associated with the increased serum level of shed syndecan- 2 seen during chronic inflammation.

\section{Chronic Inflammation Promotes MMP-7 Expression in a Colon-Region-Dependent Manner}

Since MMP-7 and MMP-14 have been shown to be involved in syndecan-2 shedding previously, ${ }^{28,29}$ we examined the expression changes of those MMPs in our experimental 
A

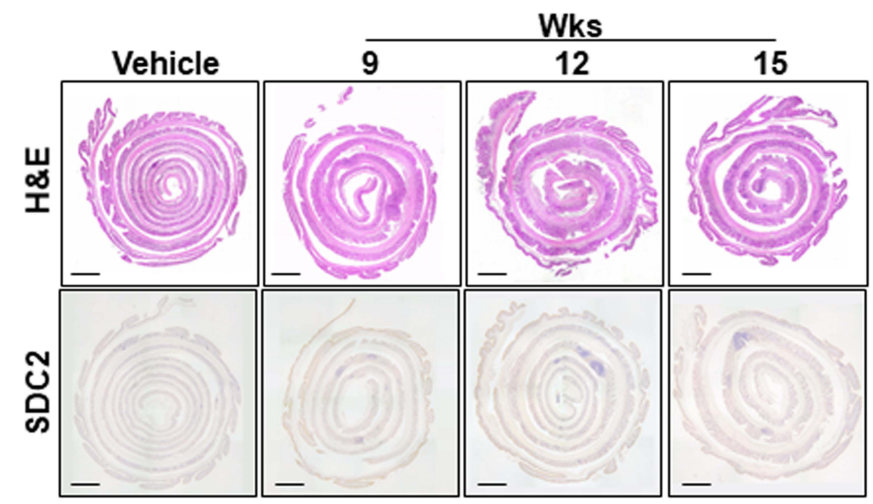

C

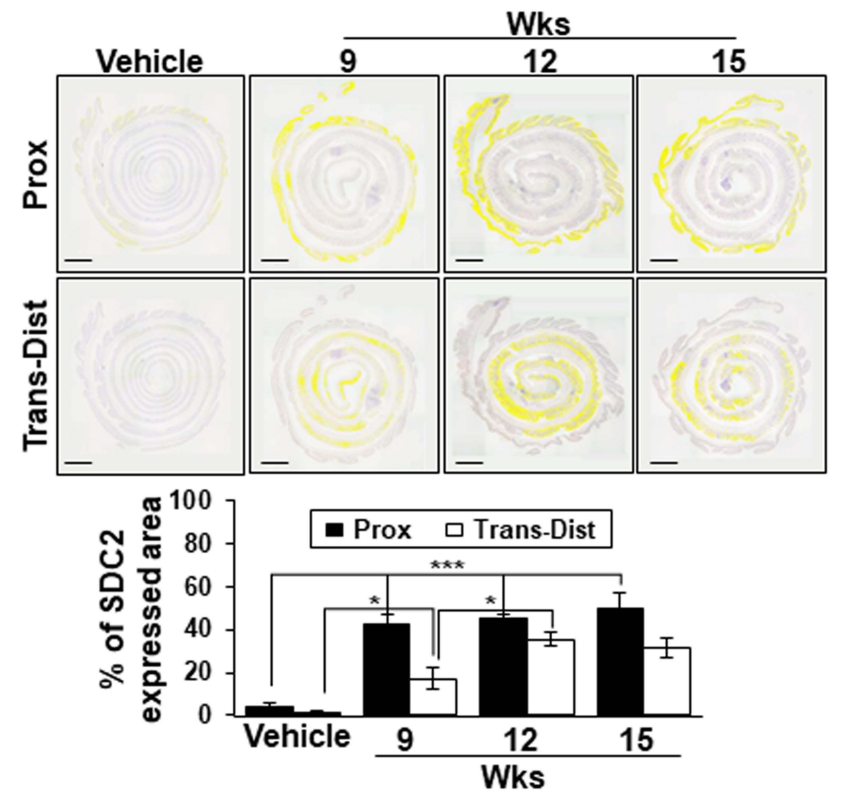

B

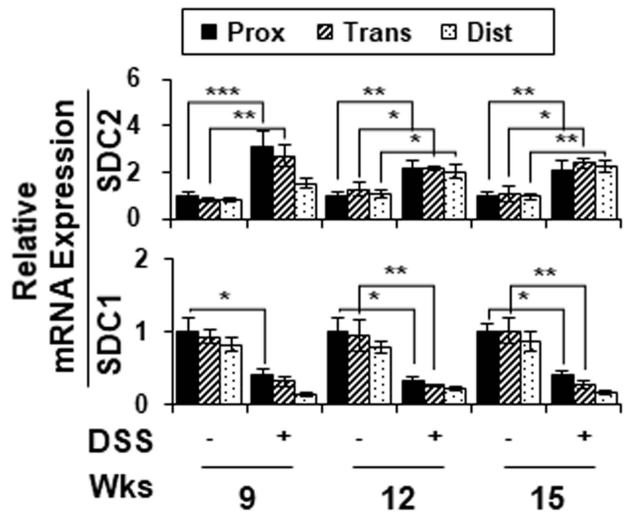

D

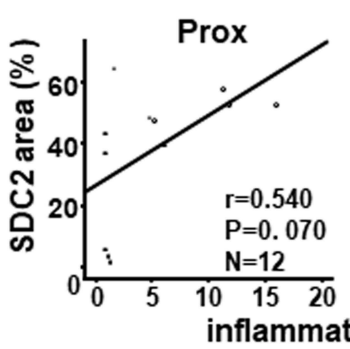

E

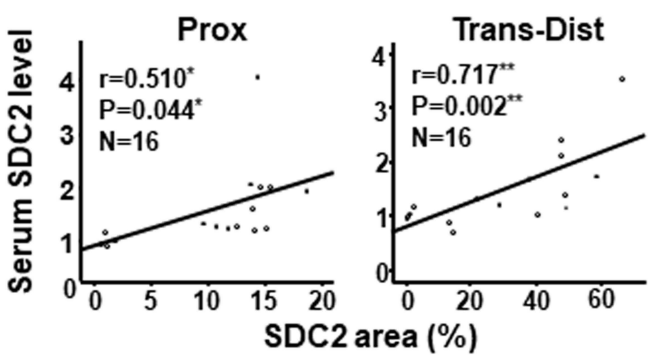

Figure 2 Serum levels of shed syndecan-2 correlate with syndecan-2 expression at trans-distal colon. (A) Inflammation induced colonic tissues were stained with H\&E (top panel) or immunostained with anti-syndecan-2 antibody at the indicated timepoints. Scale bars: 500 $\mu$. (B) Expression of syndecan-2 (SDC2) and -I (SDCI) in the indicated colon tissues were analyzed by qRT-PCR. (C) The areas expressing elevated syndecan- 2 in the proximal or trans-distal colon were digitally colored (yellow) (top panel) and analyzed with an LAS Image Analyzer (LAS ver 4.0; Leica Microsystems). Scale bars: $500 \mu \mathrm{m}$. Each colored area was calculated and graphically represented compared to vehicle (bottom panel). ${ }^{*} p<0.05$, **p $<0.01$, *** $<0.001$. (D-E) The association between the areas of syndecan-2 and inflammatory (D) and area of syndecan-2 and serum shed syndecan-2 level (E) were analyzed using correlation analysis, as applied using the ANOVA test program, SPSS (version 20.0). Note the close correlation of area of syndecan- 2 with the inflammatory area in trans-distal colon and shed syndecan-2 level in part of all colon ( $n=3 \sim 4$ mice per group).

system (Figure 3). MMP-7 expression was not detected in the colon tissues of vehicle control mice, whereas chronic colitisinduced mice exhibited upregulation of MMP-7 expression in the transverse colon at weeks 9, 12 and 15 (Figure 3A). At weeks 12 and 15, MMP-7 expression was increased in the crypt region throughout the colon, with the most dramatic increase observed in the transverse and distal colon (Figure 3A). The mRNA expression pattern of MMP-7 was found to be similar to the corresponding protein level in colon tissues (Figure 3C). In contrast, whereas the protein expression of MMP-14 in colon epithelial cells was similar regardless of the region or time point (Figure 3B), the mRNA level of MMP-14 was somewhat higher in the trans-distal colon at weeks 12 to 15 in chronic inflammation-induced mice compared to vehicle controls (Figure 3D). This may be due to the lower correlation between MMP-14 expression and colonic epithelium. Together, these data suggest that MMP-7 expression is dependent on the colonic region.

\section{Chronic Inflammation Causes}

\section{Colocalization of Syndecan-2 with MMP-7}

\section{at Distal Colonic Tissues}

To determine whether MMP-7 is directly involved in syndecan-2 shedding, we performed double immunofluorescence staining of chronic inflammation-induced colon tissues using antibodies against syndecan-2 and MMP-7. The proximal, transverse and distal colon regions were 
A

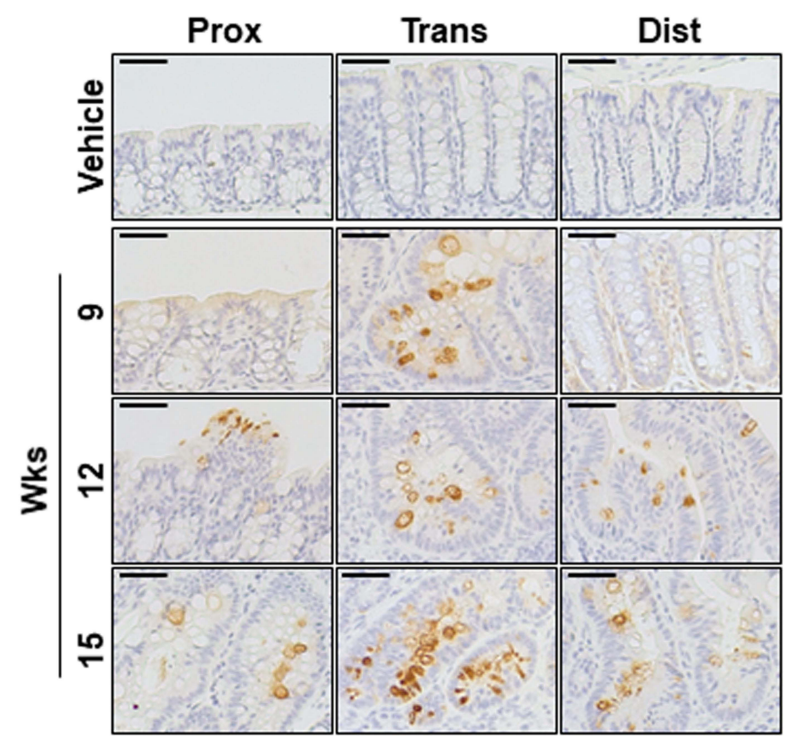

\section{C}

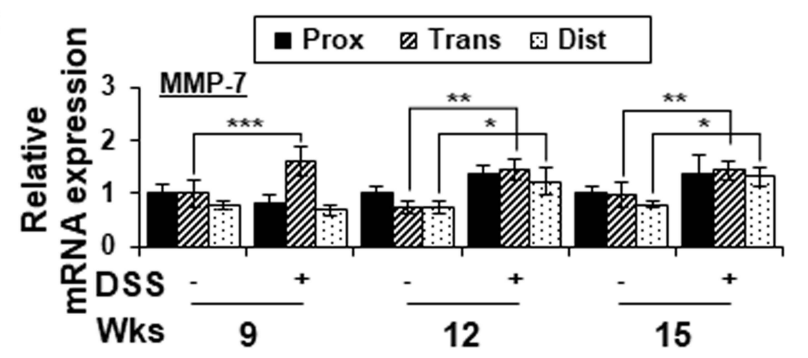

B
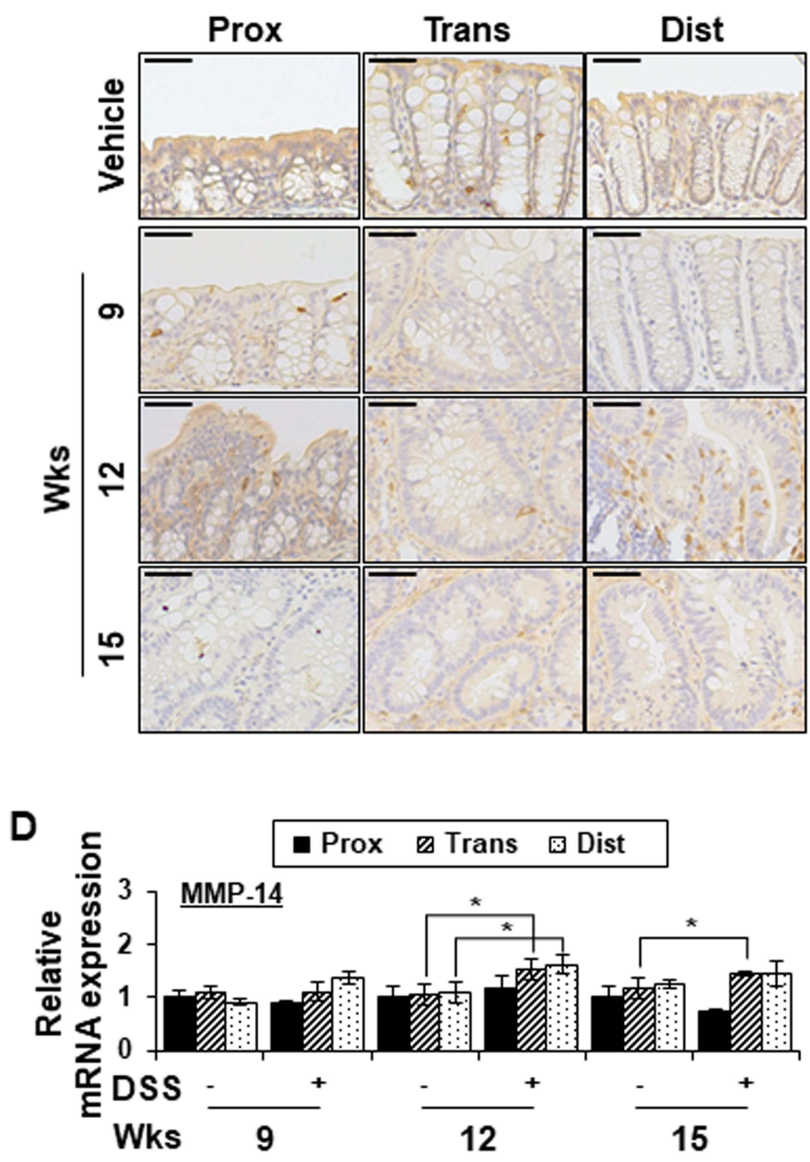

Figure 3 Chronic inflammation promotes MMP-7 expression in a colon-region-dependent manner. (A and B) Proximal, transverse and distal colon tissues from each indicated time points were immunostained with anti-MMP-7 (A) and MMP-14 (B) antibodies. Scale bars: $50 \mu \mathrm{m}$ (top panel). (C and D) The mRNA expression of MMP-7 (C) and MMP-I4 (D) from each region $(n=5)$ were analyzed by qRT-PCR. ${ }^{*} p<0.05$, ** $p<0.01,{ }^{* * *} p<0.001$.

stained and assessed for the colocation of syndecan-2 and MMP-7 (Figure 4). At week 9, syndecan-2 was observed in the proximal colonic epithelium, while MMP-7 was weak but predominantly observed in the crypt of the transverse colon, suggesting that the two molecules did not spatially or temporally colocalize (Figure 4A). Interestingly, however, at week 12 , while syndecan-2 was mainly observed in the colonic epithelium, increased MMP-7 expression was observed in both the crypt of the trans-distal colon and in the colonic epithelium. In the colonic epithelium, there was no detectable colocalization of syndecan-2 and MMP-7 in the proximal colon, but these molecules were located close together in both the transverse and distal colon. In the distal colonic epithelium, about $10 \%$ of the cells showed colocalization of syndecan-2 and MMP-7 (Figure 4B), suggesting that the extracellular domain of syndecan-2 could be shed by MMP-7 in the distal colon. Collectively, these findings suggest that syndecan-2 and MMP-7 may colocalize at the distal colon during chronic inflammation, which might be important for the shedding of syndecan-2.

\section{IL-6 Promotes Shedding of Syndecan-2 by Regulating MMP-7 Expression at the Distal Colon}

Since Kwon et al reported that IL-1 $\alpha$ promoted MMP-7 expression in colon cancer cell lines ${ }^{25}$ and Choi et al reported that IL-1 $\beta$ elevated syndecan-2 expression during inflammatory hypoxia, ${ }^{20}$ we hypothesized that proinflammatory cytokines are involved in the regulation of syndecan-2 shedding. To examine this possibility, several proinflammatory cytokines (IL-1 $\alpha$, IL-1 $\beta$, IL-6, IL-17A) that are thought to influence the upregulation of MMP-7 during chronic inflammation were analyzed (Figure 5A). Compared to vehicle control mice, chronic inflammationinduced mice did not show any alteration of IL- $1 \alpha$ but did exhibit increases in the levels of IL-1 $\beta$ and IL-17A, mostly 
A

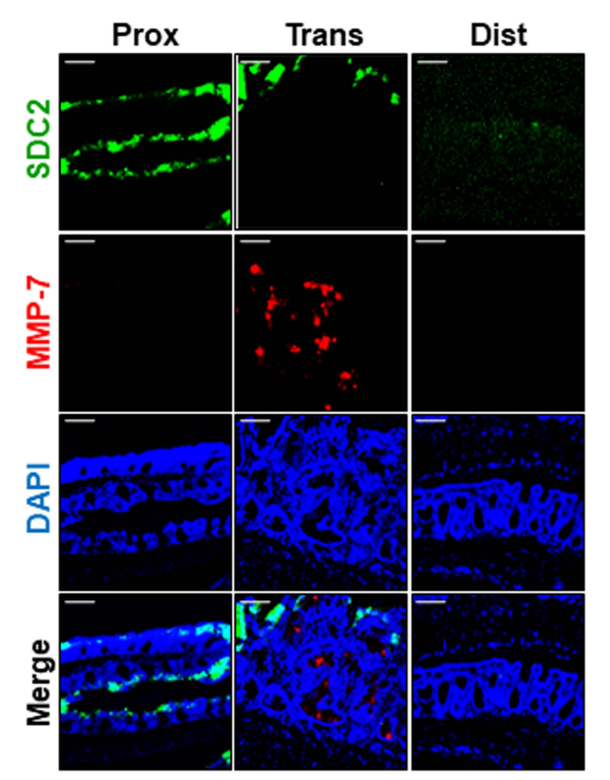

B

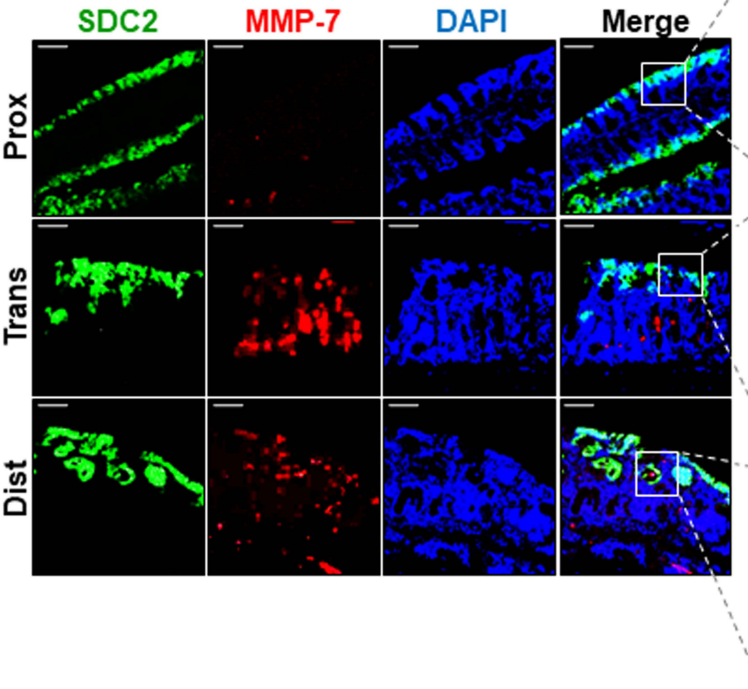

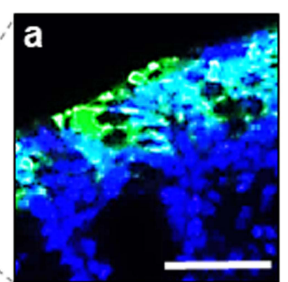
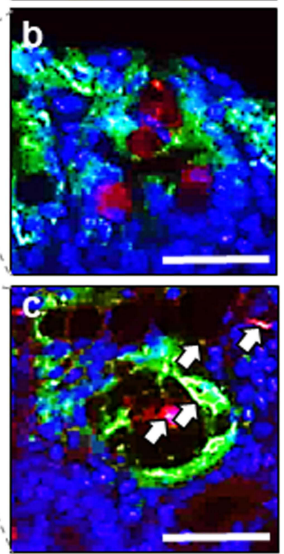

Figure 4 Chronic inflammation causes colocalization of syndecan-2 with MMP-7 at distal colonic tissues. (A and B) Paraformaldehyde fixed, paraffin embedded $4 \mu \mathrm{m}$ sections of inflammation induced colonic tissues at 9 weeks (A) and 12 weeks (B) were stained with syndecan-2 and MMP-7 primary antibody and nuclei were stained with DAPI $(n=5)$. Syndecan-2 was visualized with FITC-conjugated goat anti-mouse antibody and MMP-7 was visualized with Texas Red-conjugated goat anti-rabbit antibody. Scale bars: $100 \mu \mathrm{m}$. Magnified images of syndecan-2 and MMP-7 co-immunostained region of each proximal (a), transverse (b) and distal (c) colon. Scale bars: $50 \mu \mathrm{m}$. White arrows represent the colocalization of syndean-2 with MMP-7 in the magnified images.

at week 15. Interestingly, IL-6 exhibited a gradual elevation from week 9 to week 15 (Figure 5A). Since the level of shed syndecan-2 increased most obviously at week 15 , the cytokine analysis result suggests that IL-1 $\beta$, IL- 6 and IL-17A could be responsible for the initiation of syndecan2 shedding (Figure 1D). We therefore studied the mRNA level of each cytokine in the different colon regions (Figure 5B). At week 9, the mRNAs for all three cytokines were most prominently elevated in the transverse colon. At week 12 , the mRNA levels of IL-1 $\beta$ and IL-17A were ameliorated, but IL-1 $\beta$ was once again upregulated at week 15. Meanwhile, the mRNA level of IL-6 was maintained from weeks 9 to 15 , especially in the trans-distal colon (Figure 5B). These findings suggested that IL-1 $\beta$ and IL-6 could be considered potential candidates for syndecan-2 shedding factors. To further examine the direct effects of cytokines, we applied each cytokine to acute inflammation-induced colon tissues (treated with 3\% DSS for 4 days) rather than chronically inflamed tissues, in which we would expect there to be many unpredictable changes. We collected colonic tissues from normal and acute DSS-induced mice, treated them with these cytokines (IL-1 $\beta$, IL-6), and examined their involvement in syndecan-2 shedding (Figure 5C). In the colon tissues of normal mice, neither IL-1 $\beta$ nor IL-6 affected the mRNA expression of syndecan-2, MMP-7, or the shedding of syndecan-2 from colon tissues. In acute inflammatoryinduced colon tissues, however, there were relevant cytokine-induced alterations in these mRNA levels. IL-1 $\beta$ treatment increased the mRNA levels of syndecan- 2 and MMP-7 most prominently in the proximal region, whereas IL-6 enhanced these levels in the trans-distal colon. Interestingly, shed syndecan-2 was only detected in the culture supernatants of IL-6-treated samples, especially those from the distal region (Figure 5C, bottom). Moreover, two cancer cell lines originating from the ascending colon, HCT116 and SNU-1235, showed an increase in MMP-7 mRNA levels after the cells were treated with IL- $1 \alpha$ or IL-1 $\beta$, whereas there was no alteration in the mRNA level of MMP-7 in the descending colon-originated colon cancer cell lines, DLD-1 and SW480, following their treatment with IL-1 $\alpha$ or IL-1 $\beta$. Treatment with IL-6, in contrast, increased the mRNA level of MMP-7 in DLD-1 cells (Figure 5D). Consistent with these findings, slot blotting showed that treatment with IL- $1 \alpha$ or IL- $1 \beta$ increased the shed syndecan- 2 level 
A

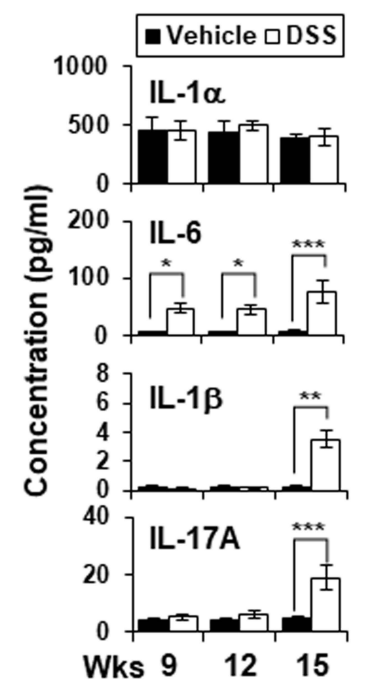

B

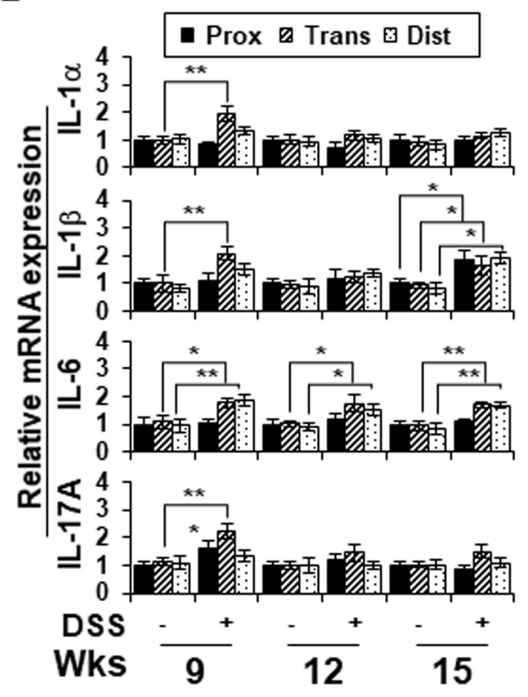

c

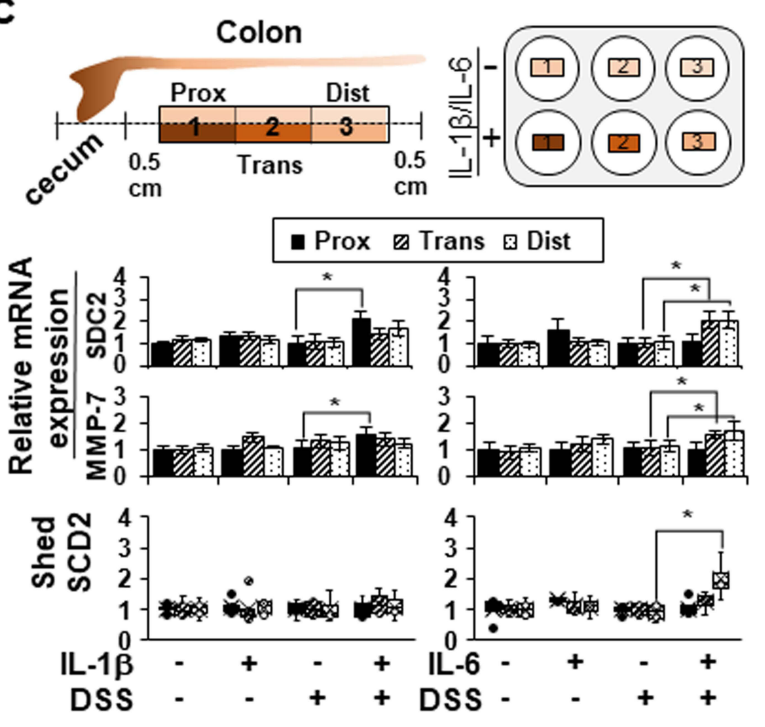

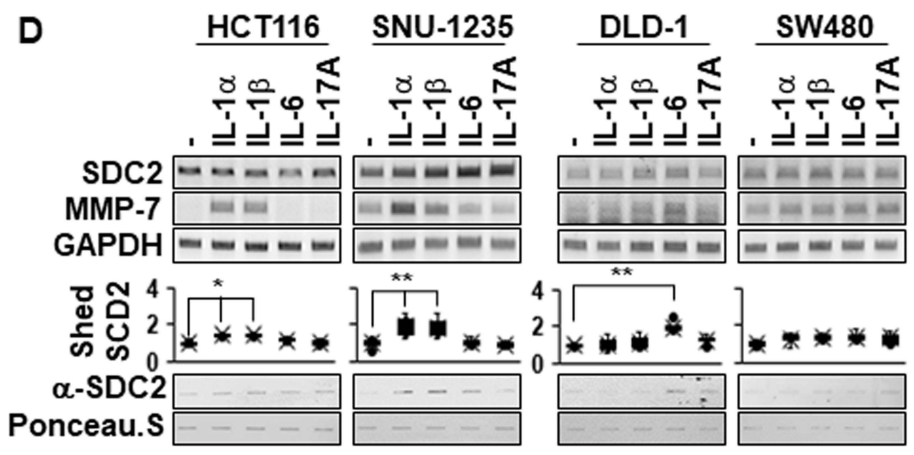

E

$\frac{\text { DLD-1 }}{-\quad+\quad+\quad+}$

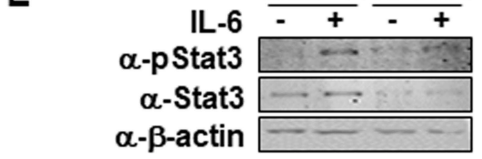

F

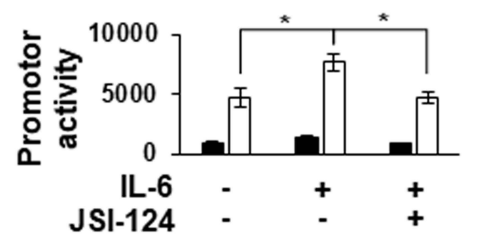

Figure 5 IL-6 promotes shedding of syndecan-2 by regulating MMP-7 expression at distal colon. (A) Serum samples $(n=6)$ were analyzed for their concentrations of various cytokines using a multiplex cytokine analysis. (B) The mRNA expression levels of IL-I $\alpha$, IL-I $\beta$, IL-6, and IL-I7A in the proximal, transverse, and distal colon on the indicated days were assessed by qRT-PCR $(n=6)$. (C) Colon tissues dissected from normal or acute DSS-induced mice administrated with $3 \%$ DSS for 4 days were ex vivo cultured and treated with $10 \mathrm{ng} / \mathrm{mL}$ of IL-I $\beta$ or $40 \mathrm{ng} / \mathrm{mL}$ of IL-6 each for $24 \mathrm{hr}$. The mRNA expression levels of syndecan-2 and MMP-7 were analyzed by qRT-PCR ( $\mathrm{n}=6$ ). The cultured media was collected and analyzed by slot blotting with anti-syndecan-2 antibody. Box-whisker plot represented the level of shed syndecan-2 using shed syndecan-2 level of vehicle as a control $(n=5)$. (D) The mRNA levels of human syndecan-2 and MMP-7 in the indicated colon cancer cell lines after treating each indicated cytokine (I ng/mL IL$1 \alpha, 10 \mathrm{ng} / \mathrm{mL}$ IL-I $\beta, 40 \mathrm{ng} / \mathrm{mL}$ IL-6 or $50 \mathrm{ng} / \mathrm{mL}$ IL-I7A) were determined by RT-PCR. GAPDH was used as the loading control. The cultured media was collected and analyzed by slot blotting with anti-syndecan-2 antibody. Box-whisker plot represented the level of shed syndecan-2 using shed syndecan-2 level of vehicle as a control. (E) After serum starvation, DLD-I cells were treated with $40 \mathrm{ng} / \mathrm{mL}$ of IL-6 for $24 \mathrm{hr}$ and then total cell lysates were immunoblotted with the indicated antibodies. (F) The cells treated with $40 \mathrm{ng} / \mathrm{mL}$ of IL- 6 in either the absence or presence of $0.5 \mu \mathrm{M}$ of JSI- I 24 were lysed with luciferase lysis buffer to measure the luciferase activity and the $\beta$ galactosidase activity. Data are shown as mean+S.D. $(n=3) .{ }^{*} p<0.05, * * p<0.01, *^{* * *} p<0.001$.

in ascending colon-originated colon cancer cell lines, whereas treatment with IL-6 induced syndecan-2 shedding in DLD-1 cells (Figure 5D).

Since IL-6 and signal transducer and activator of transcription 3 (STAT3) play important roles in the survival of intestinal epithelial cells and the development of inflammationassociated colon cancer, ${ }^{30}$ we further investigated whether the IL-6/STAT3 pathway was involved in regulating MMP-7 expression. As expected, IL-6 treatment induced phosphorylation of STAT3 in DLD-1 cells, but not in HCT116 cells (Figure 5E). Consistently, IL-6 increased MMP-7 promoter activity and a STAT3 inhibitor (JSI-124) completely abrogated these changes (Figure 5F). These findings suggest that IL-
6-STAT3 pathway may induce MMP-7 expression in distal colon to increase the shedding of syndecan- 2 .

To further investigate the direct role of MMP-7 in the extracellular shedding of syndecan-2 in colon tissues, we collected colonic tissues from acute DSS-induced mice and treated these tissues with MMP-7 in the absence or presence of an MMP inhibitor (Figure 6). Consistent with a previous report, ${ }^{24}$ we found that acute inflammation mediated by DSS induced expression of syndecan-2 predominantly in the proximal colon, but not detectable amounts of MMP-7 in the proximal colon (Figure 6A). The direct application of MMP-7 enzyme to ex vivo-cultured proximal colon tissues expressing syndecan- 2 increased the levels of shed syndecan- 


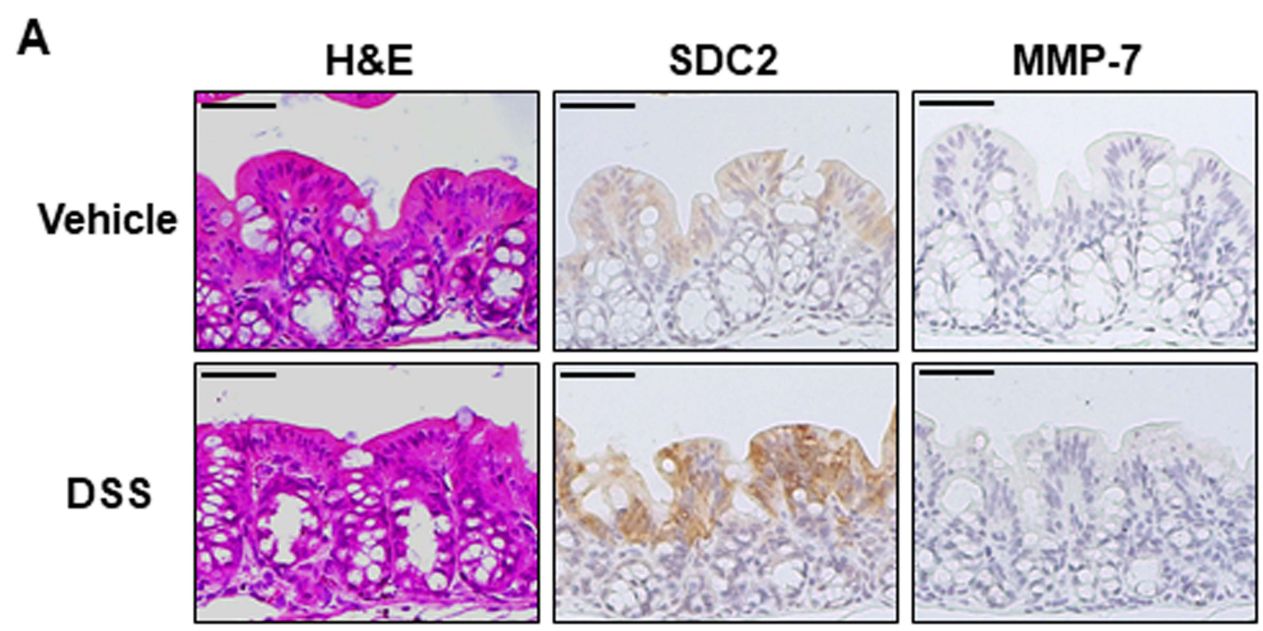

B
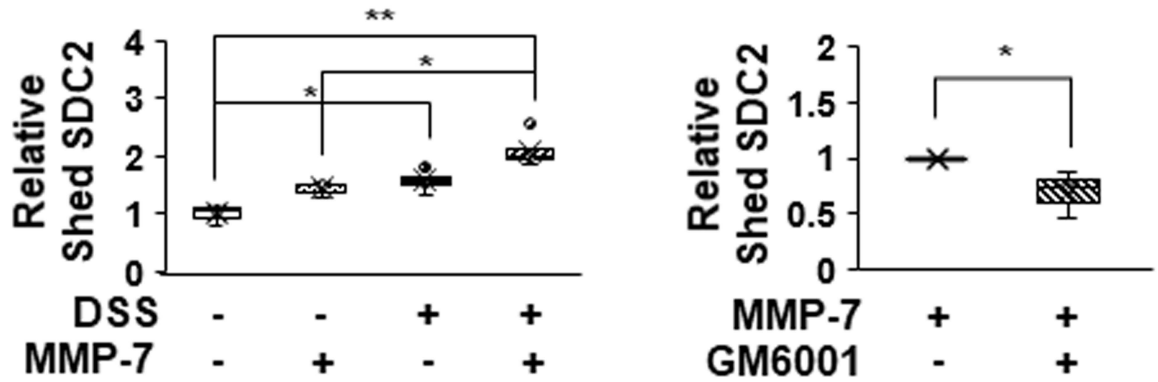

Figure 6 MMP-7 directly induces shedding of syndecan-2 in colon tissues. (A) Seven-week-old C57BL/6 mice were administrated with 3\% DSS for 4 days, and colon sections of each group were H\&E stained or immunostained with the indicated antibodies. Scale bars: $50 \mu \mathrm{M}$. (B) Colon tissues dissected from mice were ex vivo cultured and treated with MMP-7 $(320 \mathrm{nM})$ for $2 \mathrm{hr}$ in the absence (left panel, $\mathrm{n}=5$ ) or presence (right panel, $\mathrm{n}=3$ ) of MMP-7 inhibitor (GM600I). The cultured media was analyzed by slot blotting with antisyndecan-2 antibody. Box-whisker plot represented the level of shed syndecan-2 using shed syndecan-2 level of vehicle as a control ( $n=5)$. * $p<0.05$, ** $p<0.01$.

2 in the tissue culture media, and this was inhibited by cotreatment with $500 \mathrm{nM}$ MMP-7 inhibitors (GM6001) (Figure 6B), further confirming that MMP-7 mediates the extracellular domain shedding of syndecan-2 in colon tissues.

Interestingly, in an acute TNBS colitis model, which was characterized by more focal damage in distal colon than in the DSS colitis model, syndecan-2 expression was increased in all parts of colon, but MMP-7 was expressed only in proximal colon (Figure 7A). Although the syndecan-2 expression region was well associated with the inflammatory region $(\mathrm{r}=0.809, \mathrm{P}=0.015)$ in trans-distal colon (Figure $7 \mathrm{~B})$, there were no detectable amounts of shed syndecan- 2 in TNBS colitis model (Figure 7C), supporting the importance of syndecan-2 colocalization with MMP-7 in distal colon on syndecan-2 shedding during chronic inflammation.

\section{Discussion}

We previously reported that syndecan-2 expression was elevated during both chronic inflammation and cancer development, ${ }^{20,31,32}$ and that extracellular domain release of syndecan-2 occurred in cancer patients. ${ }^{21}$ Here, we further investigated whether inflammation triggered extracellular domain shedding of syndecan-2. Our results revealed that the serum levels of shed syndecan-2 were increased by chronic inflammation-mediated MMP-7 expression, and that long-term inflammation in the colon epithelium could increase the serum level of shed syndecan-2 in a DSS-induced mouse model (Figure 1). This suggests that syndecan-2 shedding requires chronic inflammation stress. Although a previous study indicated that syndecan-2 expression begins to increase in the proximal colon during acute inflammation, ${ }^{24}$ our present results showed that syndecan-2 was increased in the same region by more than $50 \%$ at week 15 of chronic inflammation (Figure 2). These findings suggest that this event requires an additional regulatory mechanism for syndecan-2 shedding. In addition, our observation that chronic inflammation induced syndecan-2 expression specifically at the 
A

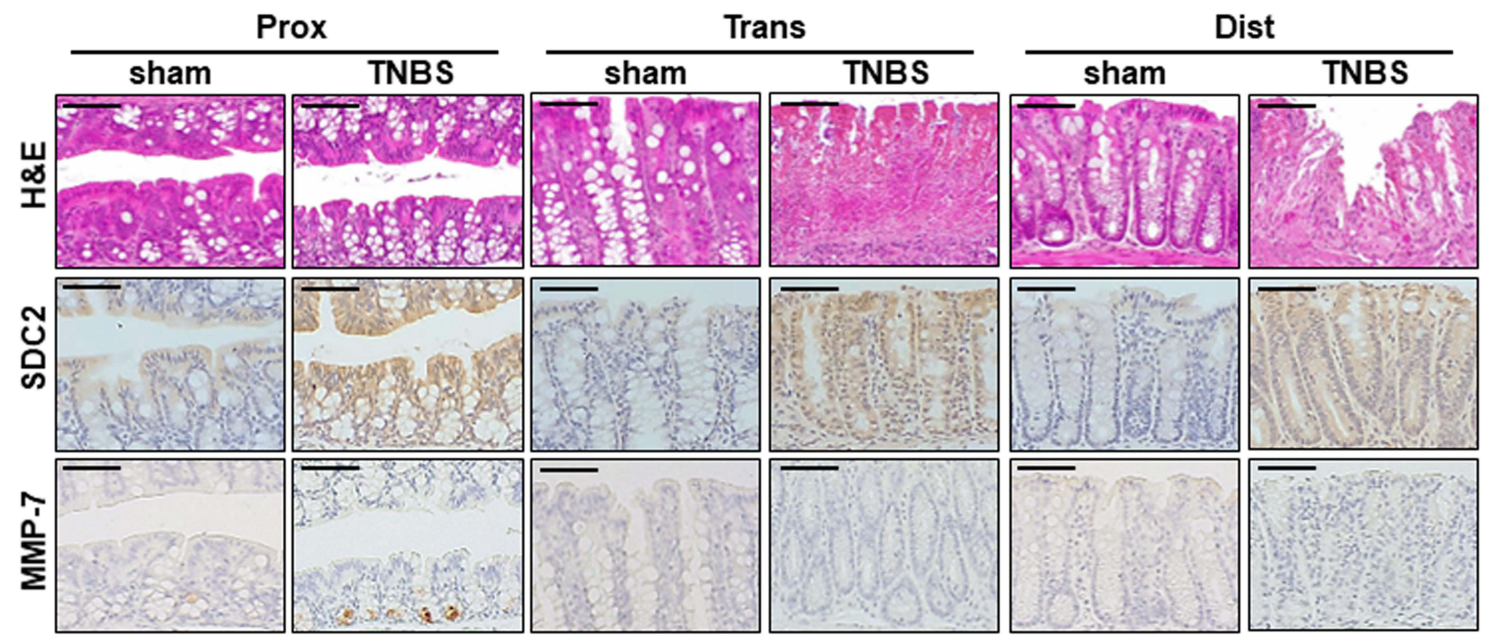

B
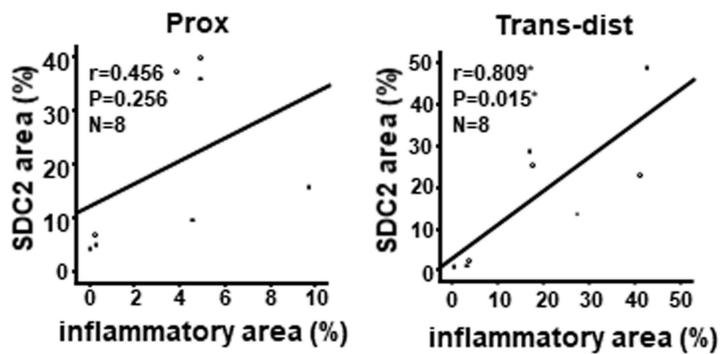

C
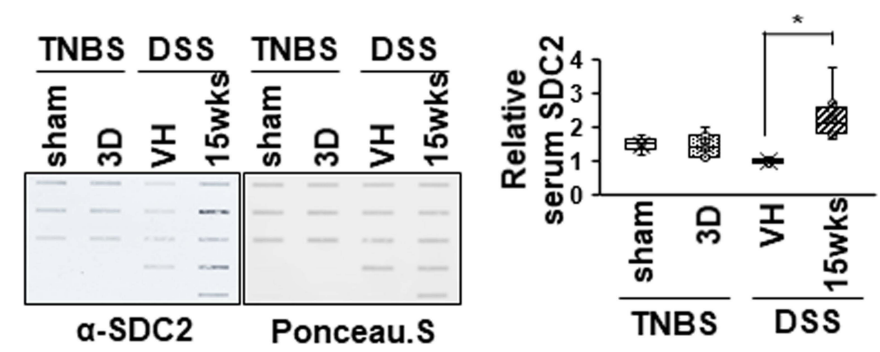

Figure 7 Serum levels of syndecan-2 are not detected in an TNBS-induced colitis mice. (A) Mouse tissues from acute TNBS model were stained with H\&E or immunostained with anti-syndecan-2 and -MMP-7 antibodies ( $n=3 \sim 4$ mice per group). Scale bars: $50 \mu$ M. (B) The associations between the syndecan-2 expression area and the inflammatory area in acute TNBS model was analyzed using correlation analysis, as applied by the ANOVA test program of SPSS (version 20.0). (C) Mice serum were collected and analyzed by slot blotting with anti-syndecan-2 polyclonal antibody. Quantitative analysis of shed syndecan-2 levels in mice serum were performed using boxwhisker plot. Shed syndecan-2 level in vehicle mice was used as a control. * $p<0.05$.

distal colon (Figure 2) suggests that site-specific syndecan2 expression is critical for its extracellular shedding.

Since MMP-7 and MMP-14 are known shedding factors for syndecan-2, ${ }^{24,28}$ we investigated the expression patterns of both proteinases (Figure 3). Our data showed that MMP-7 was increased in the transverse colon at week 9 of inflammation, especially in the intracellular vesicles of the crypt region (Figure 3A). At week 12, MMP-7 expression was frequently observed in crypt regions throughout the colon, as well as in the epithelial region (Figure 3A). To induce syndecan-2 shedding, MMP-7 must interact with syndecan-2. Colocalization of syndecan-2 and MMP-7 was not detected at week 9. However, the two proteins were observed in very close proximity within cells in the transverse colon and even colocalized each other in the distal colon at week 12 of inflammation (Figure 4), suggesting that MMP-7 may be involved in the shedding of syndecan-2 during chronic inflammation. In contrast, we did not detect the altered expression of MMP$14,{ }^{28}$ the other syndecan-2 shedding factor, in the colonic epithelial cells during chronic inflammation (Figure 3B). Collectively, these data suggest that syndecan-2 and MMP-7 are colocalized not in the proximal colon, but rather in the distal colon, which results in the shedding of syndecan-2.

Our analysis of the serum cytokine levels of DSSinduced colitic mice revealed that the levels of IL-1 $\beta$, IL6 and IL-17A were increased at week 15, but only IL-6 exhibited a gradual elevation from weeks 9 to 15 (Figure 5A). Interestingly, the mRNA level of IL-1 $\beta$ was found to increase from the proximal to distal colon at week 15 , perhaps connecting our present data to our previous report showing that IL-1 $\beta$ contributes to syndecan-2 expression during chronic inflammation. ${ }^{20}$ Although IL$1 \beta$ and IL- 6 did not influence syndecan- 2 shedding in normal colonic tissues, IL- 6 , but not IL- $1 \beta$, could increase the level of shed syndecan-2 in inflammation-induced colonic tissues, especially the distal region of ex vivocultured inflamed colonic tissues (Figure 5C), suggesting that IL-6 production during chronic inflammation 
upregulates the expression levels of both syndecan-2 and MMP-7 in the distal colon. Indeed, IL-6 treatment elevated the expression levels of both syndecan-2 and MMP-7 in distal colon-originated colon cancer cells (eg, DLD-1 cells) in parallel with an increase in the amount of shed syndecan-2 found in the conditioned media (Figure 5D). Consistently, the treatment of MMP-7 induced syndecan-2 shedding in the inflamed colon tissue culture (Figure 6). These data confirm that local expression of IL-6 is a key player in the upregulation of MMP-7 expression and the shedding of syndecan-2 in the distal colon.

Interestingly, an acute TNBS colitis model (Figure 7), which was characterized by more focal damage in distal colon than in the DSS colitis model showed increased syndecan-2 expression in all parts of colon. However, under our experimental conditions, it did not alter either the mRNA nor protein expression levels of MMP-7, and therefore the shedding of syndecan-2 remained unchanged. Together, these data support the importance of syndecan-2 colocalization with MMP-7 in distal colon on syndecan-2 shedding during chronic inflammation.

\section{Conclusion}

In the present paper, we report for the first time that the level of shed syndecan-2 is increased after long-term inflammation, and that this occurs through the promotion of MMP-7 expression. Both MMP-7 and syndecan-2 should be colocalized in a given cell to enable syndecan2 shedding. Serum-borne IL-6 is an important factor for the induction of MMP-7 expression in the distal colon region, which is a critical region for syndecan-2 shedding under inflammation. Therefore, the level of shed syndecan- 2 in the sera of colitis patients could potentially be used as a precise marker to diagnose perpetuated inflammation and monitor their status, potentially helping to guard against the development of colitis-associated cancer.

\section{Abbreviations}

SDC2, syndecan-2; DSS, dextran sulfate sodium; IL-1 $\alpha$, interleukin-1 $\alpha$, IL-1 $\beta$, interleukin-1 $\beta$; IL-6, interleukin-6; IL-17A, interleukin-17A; MMP, matrix metalloproteinase; HB-EGF, heparin-binding EGF-like growth factor; AOM, azoxymethane; TNBS, trinitrobenzene sulphonic acid; TNF- $\alpha$, tumor necrosis factor- $\alpha$; qRT-PCR, quantitative real time PCR; GAPDH, glyceraldehyde 3-phosphate dehydrogenase.

\section{Acknowledgments}

This research was supported by the National Research Foundation of Korea (NRF) grant funded by the Korea government (MSIP) (2019R1A2C2009011).

\section{Author Contributions}

All authors made substantial contributions to conception and design, acquisition of data, or analysis and interpretation of data; took part in drafting the article or revising it critically for important intellectual content; agreed to submit to the current journal; gave final approval of the version to be published; and agree to be accountable for all aspects of the work.

\section{Disclosure}

The abstract of this paper was presented at the 11th International Conference on Proteoglycans as a poster presentation with interim findings. The authors report no conflicts of interest in this work.

\section{References}

1. Medzhitov R. Origin and physiological roles of inflammation. Nature. 2008;454:428-435. doi:10.1038/nature07201

2. Kotas ME, Medzhitov R. Homeostasis, inflammation, and disease susceptibility. Cell. 2015;160:816-827. doi:10.1016/j.cell.20 15.02.010

3. Todoric J, Antonucci L, Karin M. Targeting inflammation in cancer prevention and therapy. Cancer Prev Res. 2016;9:895-905. doi:10.1158/1940-6207.CAPR-16-0209

4. Kamekura R, Nava $P$, Feng $M$, et al. Inflammation-induced desmoglein-2 ectodomain shedding compromises the mucosal barrier. Mol Biol Cell. 2015;26:3165-3177. doi:10.1091/mbc.e1503-0147

5. Guinea-Viniegra J, Zenz R, Scheuch H, et al. TNFalpha shedding and epidermal inflammation are controlled by Jun proteins. Genes Dev. 2009;23:2663-2674. doi:10.1101/gad.543109

6. Gomez MI, Sokol SH, Muir AB, et al. Bacterial induction of TNF-alpha converting enzyme expression and IL-6 receptor alpha shedding regulates airway inflammatory signaling. $J$ Immunol. 2005;175:1930-1936. doi:10.4049/jimmunol.175.3.1930

7. Hayashida K, Bartlett A, Chen Y, et al. Molecular and cellular mechanisms of ectodomain shedding. Anat Rec. 2010;293 (6):925-937. doi:10.1002/ar.20757

8. Ribeiro AS, Albergaria A, Sousa B, et al. Extracellular cleavage and shedding of P-cadherin: a mechanism underlying the invasive behaviour of breast cancer cells. Oncogene. 2010;29:392-402. doi:10.1038/onc.2009.338

9. Mannello F, Tonti G, Medda V, et al. Increased shedding of soluble fragments of P-cadherin in nipple aspirate fluids from women with breast cancer. Cancer Sci. 2008;99:2160-2169. doi:10.1111/j.13497006.2008.00921.x

10. Gordon KJ, Dong M, Chislock EM, et al. Loss of type III transforming growth factor beta receptor expression increases motility and invasiveness associated with epithelial to mesenchymal transition during pancreatic cancer progression. Carcinogenesis. 2008;29:252-262. doi:10.1093/carcin/bgm249 
11. Finger EC, Turley RS, Dong $M$, et al. TbetaRIII suppresses non-small cell lung cancer invasiveness and tumorigenicity. Carcinogenesis. 2008;29:528-535. doi:10.1093/carcin/bgm289

12. Elderbroom JL, Huang JJ, Gatza CE, et al. Ectodomain shedding of T $\beta$ RIII is required for T $\beta$ RIII-mediated suppression of TGF- $\beta$ signaling and breast cancer migration and invasion. Mol Biol Cell. 2014;25:2320-2332. doi:10.1091/mbc.e13-09-0524

13. Götte M. Syndecans in inflammation. FASEB J. 2003;17:575-591. doi:10.1096/fj.02-0739rev

14. Hayashida K, Parks W, Park PW. Syndecan-1 shedding facilitates the resolution of neutrophilic inflammation by removing sequestered CXC chemokines. Blood. 2009;114:3033-3043. doi:10.1182/blood2009-02-204966

15. Xu J, Park PW, Kheradmand F, et al. Endogenous attenuation of allergic lung inflammation by syndecan-1. $J$ Immunol. 2014;174:5758-5765. doi:10.4049/jimmunol.174.9.5758

16. Wang X, Chen Y, Song Y, et al. Activated Syndecan-1 shedding contributes to mice colitis induced by dextran sulfate sodium. Dig Dis Sci. 2010;56:1047-1056. doi:10.1007/s10620-010-1398-8

17. Zhang Y, Wang Z, Liu J, et al. Cell surface-anchored syndecan-1 ameliorates intestinal inflammation and neutrophil transmigration in ulcerative colitis. J Cell Mol Med. 2017;21:13-25. doi:10.1111/ jcmm.12934

18. Wu H, Zhou Q, Xie J, et al. Syndecan-4 shedding is involved in the oxidative stress and inflammatory responses in left atrial tissue with valvular atrial fibrillation. Int J Clin Exp Pathol. 2015;8:6387-6396.

19. Tan X, Khalil N, Tesarik C, et al. Th1 cytokine-induced syndecan-4 shedding by airway smooth muscle cells is dependent on mitogen-activated protein kinases. Am J Physiol Lung Cell Mol Physiol. 2012;302:700-710. doi:10.1152/ajplung.00167.2011

20. Choi S, Chung $\mathrm{H}$, Hong $\mathrm{H}$, et al. Inflammatory hypoxia induces syndecan-2 expression through IL-1 $\beta$-mediated FOXO3a activation in colonic epithelia. FASEB J. 2017;31:1516-1530. doi:10.1096/ fj.201601098R

21. Choi S, Choi Y, Jun E, et al. Shed syndecan-2 enhances tumorigenic activities of colon cancer cells. Oncotarget. 2015;6:3874-3886. doi:10.18632/oncotarget.2885

22. Clasper S, Vekemans S, Fiore M, et al. Inducible expression of the cell surface heparan sulfate proteoglycan syndecan-2 (fibroglycan) on human activated macrophages can regulate fibroblast growth factor action. $J$ Biol Chem. 1999;274:24113-24123. doi:10.1074/ jbc.274.34.24113
23. Teix T, Nieto-blanco P, Vilella R, et al. Syndecan-2 and -4 expressed on activated primary human $\mathrm{CD} 4+$ lymphocytes can regulate $\mathrm{T}$ cell activation. Mol Immunol. 2008;45(10):2905-2919. doi:10.1016/j. molimm.2008.01.033

24. Hong H, Song HK, Hwang ES, et al. Up-regulation of syndecan-2 in proximal colon correlates with acute inflammation. FASEB J. 2019;10:11381-11395. doi:10.1096/fj.201900561R

25. Kwon M, Hong E, Choi Y, et al. Interleukin-1 $\alpha$ promotes extracellular shedding of syndecan-2 via induction of matrix metalloproteinase-7 expression. Biochem Biophys Res Commun. 2014;446 (2):487-492. doi:10.1016/j.bbrc.2014.02.142

26. Wang L, An J, Song S, et al. Electroacupuncture preserves intestinal barrier integrity through modulating the gut microbiota in DSS-induced chronic colitis. Life Sci. 2020;15:261-118473.

27. Royal JM, Reeves MA, Matoba N. Repeated oral administration of a KDEL-tagged recombinant cholera toxin B subunit effectively mitigates DSS colitis despite a robust. Immunogenic Response Toxins. 2019;11(12):678.

28. Lee Y, Park J, Cheon D, et al. Processing of syndecan-2 by matrix metalloproteinase-14 and effect of its cleavage on VEGF-induced tube formation of HUVECs. Biochem J. 2017;474:3719-3732. doi:10.1042/BCJ20170340

29. Choi S, Kim J, Park J, et al. The matrix metalloproteinase-7 regulates the extracellular shedding of syndecan-2 from colon cancer cells. Biochem Biophys Res Commun. 2012;417(4):1260-1264. doi:10.1016/j.bbrc.2011.12.120

30. Grivennikov S, Karin E, Terzic J, et al. IL-6 and STAT3 are required for survival of intestinal epithelial cells and development of colitis associated cancer. Cancer Cell. 2009;15(2):103-113. doi:10.1016/j. ccr.2009.01.001

31. Lee JH, Park H, Chung H, et al. Syndecan-2 regulates the migratory potential of melanoma cells. J Biol Chem. 2009;284:27167-27175. doi:10.1074/jbc.M109.034678

32. Park H, Kim Y, Lim Y, et al. Syndecan-2 mediates adhesion and proliferation of colon carcinoma cells. J Biol Chem. 2002;277 (33):29730-29736. doi:10.1074/jbc.M202435200
Journal of Inflammation Research

\section{Publish your work in this journal}

The Journal of Inflammation Research is an international, peerreviewed open-access journal that welcomes laboratory and clinical findings on the molecular basis, cell biology and pharmacology of inflammation including original research, reviews, symposium reports, hypothesis formation and commentaries on: acute/chronic inflammation; mediators of inflammation; cellular processes; molecular mechanisms; pharmacology and novel anti-inflammatory drugs; clinical conditions involving inflammation. The manuscript management system is completely online and includes a very quick and fair peerreview system. Visit http://www.dovepress.com/testimonials.php to read real quotes from published authors. 